\title{
SEISMIC RESPONSES OF RC BRACED FRAMES WITH BUCKLING-RESTRAINED BRACES CONNECTED TO CORBELS
}

\author{
An-chin Wu ${ }^{1}$, Keh-chyuan Tsai ${ }^{2,}{ }^{*}$, Ting-li Lin ${ }^{3}$, Ching-yi Tsai ${ }^{4}$ and Kung-juin Wang ${ }^{5}$ \\ ${ }^{I}$ Associate researcher, National Center for Research on Earthquake Engineering, Taipei, Taiwan, China \\ ${ }^{2}$ Professor, Department of Civil Engineering, National Taiwan University, Taipei, Taiwan, China \\ ${ }^{3}$ Research assistant, Department of Civil Engineering, National Taiwan University, Taipei, Taiwan, China \\ ${ }^{4}$ Post doctor, Department of Civil Engineering, National Taiwan University, Taipei, Taiwan, China \\ ${ }^{5}$ Technologist, Department of Civil Engineering, National Taiwan University, Taipei, Taiwan, China \\ *(Corresponding author: E-mail: kctsai@ntu.edu.tw)
}

\section{A B S T R A C T}

The paper is a continuation of the investigation on a newly developed bracing system featured by the zigzag configured braced frame for reinforced concrete (RC) constructions. A 12 -story RC frame equipped with buckling-restrained braces (BRBs) is investigated as a prototype building. The feasibility and performance of the proposed BRB-to-RC connection are investigated using a cyclic loading procedure on a full-scale beam-to-column sub-assemblage specimen selected from the typical floor. No failure was observed in the steel gusset bracket or at the RC corbels throughout the tests. Seismic performance of the prototype building was further studied using a total of 240 ground accelerations in the building response history analyses. Analytical results suggest that the effects of system's high mode vibrations are moderate. The peak horizontal tension force demand on the steel gusset bracket is found about $70 \%$ of the sum of the two maximum horizontal strength components computed from the two joining BRBs.
A R T I C LE H I S TORY

$\begin{array}{ll}\text { Received: } & \text { 24 July } 2019 \\ \text { Revised: } & \text { 7 February } 2020 \\ \text { Accepted: } & \text { 7 February } 2020\end{array}$

Accepted: $\quad 7$ February 2020

\section{K E Y W O R D S}

Buckling-restrained brace; reinforced concrete building; corbel;

beam-to-column joint;

nonlinear response history analysis

\section{Introduction}

Buckling-restrained braces (BRBs) are characterized by symmetric hysteresis behavior, high ductility, and stable energy dissipation capability $[1,2]$, which has led to extensive research and applications in various structural systems [3]. However, the research and applications that adopt $\mathrm{BRBs}$ for reinforced concrete (RC) constructions appear to be rather limited and confined to the retrofitting of existing RC structures. Several methods of using $\mathrm{BRBs}$ to strengthen $\mathrm{RC}$ buildings have been proposed, such as connecting $\mathrm{BRB}$ end gussets to $\mathrm{RC}$ frame corners directly [4], positioning a braced steel frame inside the RC structure [5], and attaching a local or global bracing system to the exterior RC frame [6,7]. For new RC buildings, the connection between braces and $\mathrm{RC}$ members can be achieved with more choices. Steel brackets with BRB gussets have been embedded into the beamto-column joints to brace a new RC parking structure at an airport [8]. A new building was constructed using $\mathrm{BRBs}$ in precast $\mathrm{RC}$ frames to resist lateral earthquake loads [9]. Seismic responses of a full-scale $\mathrm{RC}$ frame with steel cast-in anchor brackets to connect BRBs and RC members was verified through hybrid and cyclic loading tests [10]. Even though the performance of various BRB connections can be found in these reports, the detailing and construction procedures of the $\mathrm{BRB}$ end brackets and the $\mathrm{RC}$ frames are still very challenging. In addition, BRBs can develop significant axial forces, which may impose the adjacent RC members with rather complicated and unfavorable loads. They may even significantly alter the expected force distribution of the adjoining members. Furthermore, the damage to adjacent RC members during earthquakes may gradually impair the expected BRB performance.

To resolve some of the aforementioned unfavorable issues when applying BRBs in new RC constructions, a Japanese research team proposed a novel bracing system [11]. As shown in Fig. 1, the BRBs are structured continuously along the height of the braced span. Each two adjacent BRBs share the same gusset, attached immediately adjacent to the RC beam-tocolumn joint. In such configuration, the beams in the braced span are not used. The BRB gusset connection consists of pre-installed bolts to transmit the horizontal tensions, and two RC corbels to resist the vertical shears induced from the BRB forces. In comparison with BRB gussets installed at the frame corners, gussets in this system are affixed to the side of the beam-to-column joints, reducing the potential for unfavorable shear failure in the braced column because of the impairment of the column slenderness. Seismic performance of the innovative BRB-to-RC frame connection was verified through cyclic loading tests on four half-scale sub-assemblies [11]. Nonlinear response history analyses (NLRHA) of a 12-story building were performed to assess the influence of the BRB connection flexibility on the dynamic response of the new bracing system [12]. The results showed that the deformations of the corbels may lead to a slight increase of the inter-story drift demands on the entire building. The tensile force demands on the BRB connections could be significantly affected by the higher mode effects of the structural system after the yielding of the braces. This might be unnoticed from a static point of view, leading to an unconservative bolt design. However, the horizontal tension force demands were not quantified in their study. In addition, the gap between the gusset bracket and the corbels had to be filled with high-strength non-shrink grout after the gusset bracket was properly fastened by the pre-stressing bolts. Thus, the corresponding side surface of the $\mathrm{RC}$ column must be constructed sufficiently flat and plumb.

In this study, the locations of the BRB-to-RC frame connection proposed by [11] are adopted, but the gusset-to-column connection details and the construction procedures are modified (Fig.2). This could provide an alternative in implementing connection design for the aforementioned novel bracing system. During the construction, the BRB gusset bracket is placed adjacent to the beam-to-column joint as part of the concrete formworks and connected to the beam longitudinal reinforcements through the couplers welded to the back of the gusset bracket. After the concrete hardens, the gusset bracket, the column, and the corbels are integrated together without gaps. This construction process is quite common in typical steel reinforced concrete construction. To investigate the influence of the static and dynamic responses of the structural system on the design force demands of the modified connection, a 12-story RC building was considered as a prototype (Fig. 1). NLRHA were conducted using a PISA3D [13] model and a total of 240 ground accelerations. Cyclic loading test was conducted on a beam-tocolumn joint sub-assemblage specimen selected from the tenth floor (Fig. 2) to verify seismic performance of the proposed connection. The particular objectives of this study: (1) develop the design and construction procedures for connections of BRBs zigzag configured in RC frames; (2) conduct a proof-of-concept test for the proposed connection details; (3) investigate the seismic efficiency of BRBs in the RC structure and the higher mode effects of the structural system on RC beams adjacent to BRBs; (4) create a test setup using electro-servo hydraulic actuators to simulate the BRB force components and control the variation of the beam axial forces; and (5) inspect the effects of beam longitudinal reinforcements anchored to the gusset bracket on the beam response and the corbel shear resistance. 

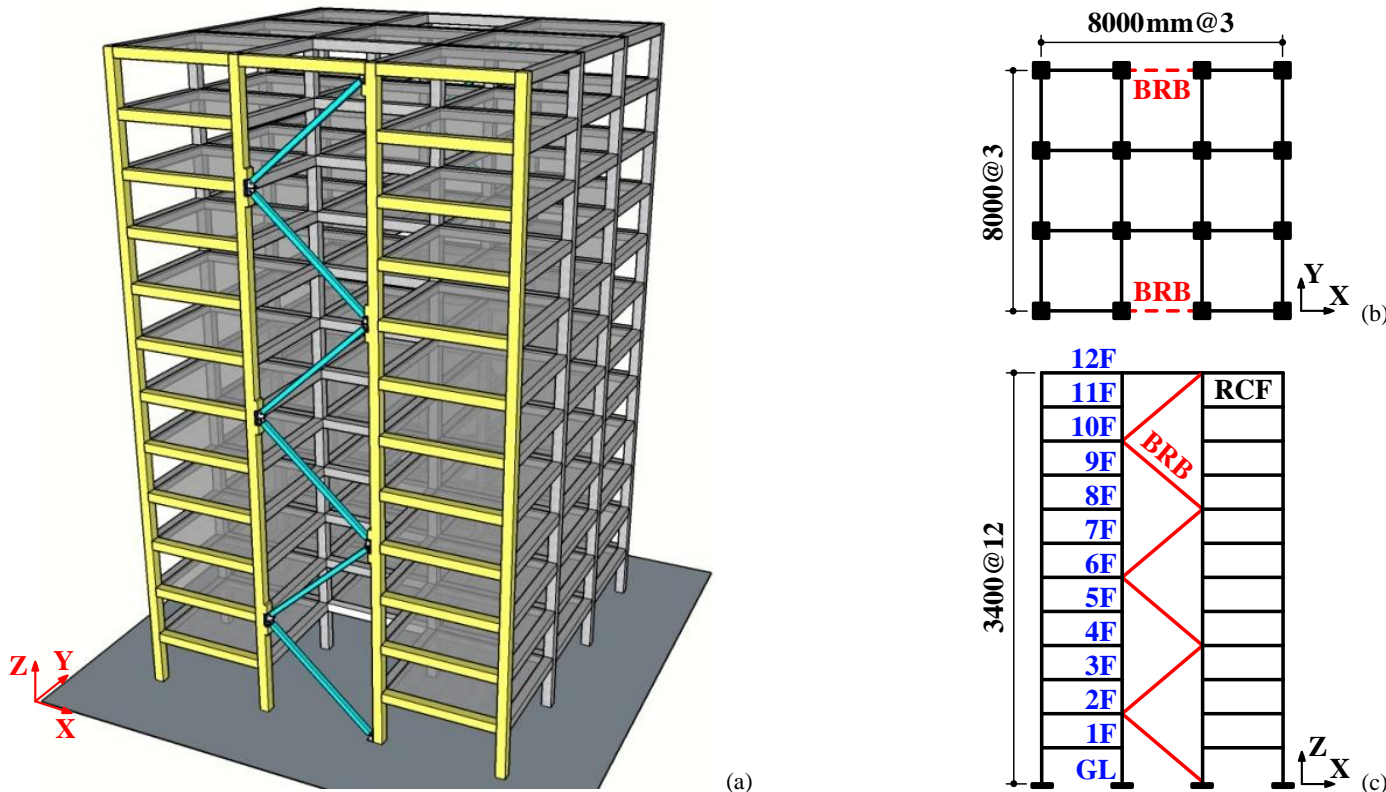

Fig. 1 (a) Structural perspective and BRB configuration, (b) structural floor plan, and (c) frame elevation in the X-direction of the prototype building

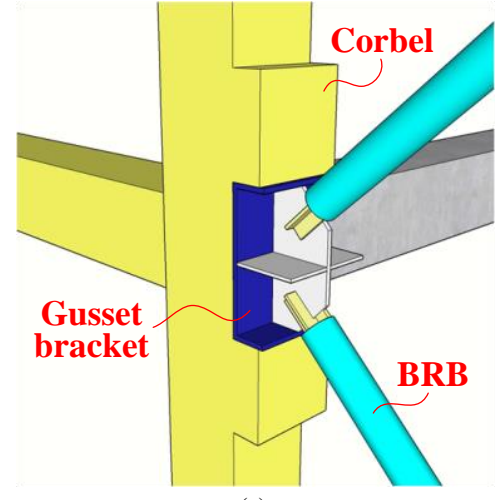

(a)

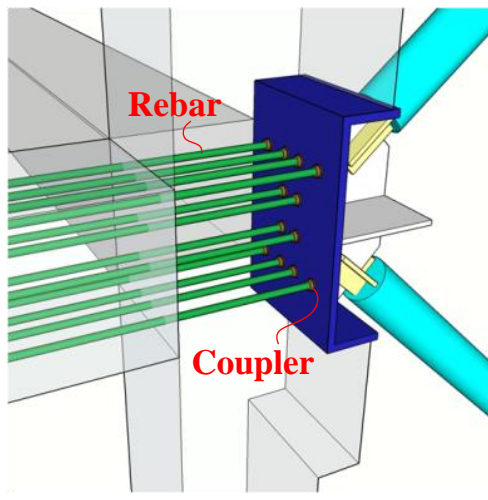

(b)

Fig. 2 Details of the (a) BRB-to-gusset bracket and (b) beam-to-gusset bracket connections

\section{Design of a 12-story RC prototype building}

A 12-story RC building located in Chiayi City was planned as a hospital with consideration of the typical architecture layout of new RC structures in Taiwan. As shown in Fig. 1, the structural plane was configured as an $\mathrm{H}$ shape with each span of $8 \mathrm{~m}$ in both directions. Each story height was $3.4 \mathrm{~m}$ with a $150 \mathrm{~mm}$ thick RC floor slab. The dual structural system in the Xdirection consisted of moment resisting frames and BRBs, while only moment resisting frames were adopted in the Y-direction. Instead of adopting link beams, the BRBs were configured in a zigzag in the two exterior $\mathrm{X}$ directional middle bays. Each BRB was arranged to pass through two stories to diminish the effect on the lighting and a top beam was placed to increase the efficiency of the top BRB. The design concrete compressive strength was $35 \mathrm{MPa}$, and CNS SD420 steel (420 MPa as the nominal yield strength) was adopted for the reinforcements.

In comparison with the steel structure, the overall stiffness ratio of entire structural frames to BRBs in the combined system is typically higher. Thus, engineers are recommended arranging a sufficient number of BRBs to improve the lateral force resisting efficiency of BRBs in the structural system. In this case, the lateral forces for BRBs and moment frames in the two braced frames were designed to be $40 \%$ of the total X-directional stiffness, and the BRBs were designed to have $70 \%$ of the lateral forces in a single braced frame. As a result, the BRBs in the two braced spans were responsible to resist $28 \%$ of the total $\mathrm{X}$-directional story shears. The BRB steel core was designed using CNS SN490B steel (325 MPa as the nominal yield strength) and the corresponding effective stiffness factor [2] was specified as 1.3. When the structural system is subjected to the higher mode effects, the two adjacent BRBs connected to the same gusset may be subjected to tension or compression forces simultaneously, leading to a significant axial force demand on the braced beam. Based on the capacity design concept, the maximum tensile $\left(T_{\max }\right)$ and compressive $\left(C_{\max }\right)$ force demands of the braced beam could be conservatively taken as the horizontal resultants induced from the two maximum tensile and compressive strengths $\left(P_{T, \max }\right.$ and $\left.P_{C, \max }\right)$ developed in the pair of BRBs, respectively. Nevertheless, local tension or compression demands arising from higher mode vibrations were found to not coincide with the peak inter-story drifts of the structural system [12]. Because of the essential difference between the force resisting capacities of the RC member in tension and compression, it appears that the tensile resistance of the braced beam should be specifically investigated. In order to avoid an overconservative and uneconomical design, the longitudinal reinforcements in the braced beam were designed to sustain a reduced tension demand of $0.7 T_{\max }$ The adopted force factor of 0.7 was based on the NLRHA results of the structural system as illustrated later in this paper.

The commercial software SAP2000 [14] was adopted for the structural design and elastic analysis of the prototype building. The RC beams and columns were modeled by line elements, and the beam and column ends were specified with full rigid end zones. The flexural rigidity for all RC member was specified as $70 \%$ of the product of the modulus of elasticity of the concrete and the gross moment inertia. The BRBs were represented by truss elements. A short rigid beam was established to link the BRB work point on the column surface and the beam-column intersection (Fig. 3). The floor slabs were modeled using membrane elements to distribute vertical loads to beams. These membrane elements were constrained as a rigid diaphragm, but the rigid constraints at the nodes next to $\mathrm{BRB}$ work point nodes were released to allow variations of the braced beam axial forces. The P-Delta effects and a $5 \%$ eccentricity for the effects of accidental torsion were considered in the analysis. RC member sizes and the story weight are listed in Tables 1 and 2 . The cross-sections of the braced beams were larger than those of other beams in the same level because of the significant axial force demands from the BRBs. The design capacities of the BRBs and braced beams are shown in Table 3. Factors of 1.2 for material overstrength, 1.3 for strain hardening, and 1.15 for compression strength adjustment were considered to estimate the 
expected BRB maximum strengths $\left(P_{T, \max }\right.$ and $\left.P_{C, \max }\right)$. The structural design results complied with the requirements for beam and column moment, beamto-column joint shear capacities, and strong column-weak beam in the model seismic building codes [15]. The modal analysis results indicated that the first, second, and third mode vibration periods were respectively 1.37 (Ydirectional translation), 1.28 (X-directional translation), and 1.08 seconds (torsion).

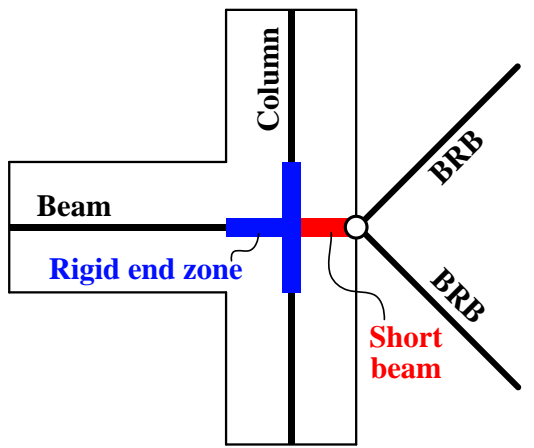

Fig. 3 Analytical model for the beam-to-column joint

Table 1

Floor weights and RC member sizes in the Y-direction

\begin{tabular}{|c|c|c|c|c|c|c|c|c|}
\hline \multirow[b]{2}{*}{ Story } & \multirow[b]{2}{*}{$\begin{array}{l}\text { Weight } \\
(\mathrm{kN})\end{array}$} & \multirow{2}{*}{$\begin{array}{c}\text { Weight per } \\
\text { unit } \\
\text { area } \\
\left(\mathrm{kN} / \mathrm{m}^{2}\right) \\
\end{array}$} & \multicolumn{3}{|c|}{ Column section } & \multicolumn{3}{|c|}{ Beam section } \\
\hline & & & $b(\mathrm{~mm})$ & $h(\mathrm{~mm})$ & $\rho(\%)$ & $b(\mathrm{~mm})$ & $h(\mathrm{~mm})$ & $\rho(\%)$ \\
\hline $12 \mathrm{~F}$ & 4573 & 10.21 & \multirow{4}{*}{600} & \multirow{4}{*}{600} & \multirow{4}{*}{2.25} & \multirow{4}{*}{500} & \multirow{4}{*}{600} & \multirow{4}{*}{1.69} \\
\hline $11 \mathrm{~F}$ & 4719 & 10.53 & & & & & & \\
\hline $10 \mathrm{~F}$ & 4748 & 10.60 & & & & & & \\
\hline $9 \mathrm{~F}$ & 4719 & 10.53 & & & & & & \\
\hline $8 \mathrm{~F}$ & 5276 & 11.78 & \multirow{6}{*}{800} & \multirow{6}{*}{800} & \multirow{6}{*}{2.54} & \multirow{9}{*}{500} & \multirow{9}{*}{800} & \multirow{9}{*}{2.04} \\
\hline $7 F$ & 5420 & 12.10 & & & & & & \\
\hline $6 \mathrm{~F}$ & 5545 & 12.38 & & & & & & \\
\hline $5 \mathrm{~F}$ & 5512 & 12.30 & & & & & & \\
\hline $4 \mathrm{~F}$ & 5545 & 12.38 & & & & & & \\
\hline $3 \mathrm{~F}$ & 5512 & 12.30 & & & & & & \\
\hline $2 \mathrm{~F}$ & 5599 & 12.50 & \multirow{3}{*}{900} & \multirow{3}{*}{900} & \multirow{3}{*}{2.81} & & & \\
\hline $1 \mathrm{~F}$ & 5708 & 12.74 & & & & & & \\
\hline Base & 560 & 11.80 & & & & & & \\
\hline
\end{tabular}

Table 2

$\mathrm{RC}$ member sizes in the $\mathrm{X}$-direction

\begin{tabular}{|c|c|c|c|c|c|c|c|c|c|}
\hline \multirow{2}{*}{ Story } & \multicolumn{3}{|c|}{ Column section } & \multicolumn{3}{|c|}{ Beam section } & \multicolumn{3}{|c|}{ Braced beam section } \\
\hline & $b(\mathrm{~mm})$ & $h(\mathrm{~mm})$ & $\rho(\%)$ & $b(\mathrm{~mm})$ & $h(\mathrm{~mm})$ & $\rho(\%)$ & $b(\mathrm{~mm})$ & $h(\mathrm{~mm})$ & $\rho(\%)$ \\
\hline $12 \mathrm{~F}$ & & & & & & & 500 & 600 & 2.03 \\
\hline $11 \mathrm{~F}$ & & 600 & & & 600 & 211 & - & - & - \\
\hline $10 \mathrm{~F}$ & 600 & & & 400 & & & 500 & 600 & 2.03 \\
\hline $9 \mathrm{~F}$ & & & & & & & - & - & - \\
\hline $7 \mathrm{~F}$ & & & & & & & ${ }_{-}^{000}$ & - & 2.03 \\
\hline $6 \mathrm{~F}$ & 800 & 800 & 254 & & & & 600 & 700 & 2.33 \\
\hline $5 \mathrm{~F}$ & & & & 500 & 700 & 174 & - & - & \\
\hline $4 \mathrm{~F}$ & & & & 500 & 700 & 1.14 & 600 & 700 & 2.71 \\
\hline $3 \mathrm{~F}$ & & & & & & & - & - & - \\
\hline $\begin{array}{l}2 \mathrm{~F} \\
1 \mathrm{~F}\end{array}$ & 900 & 900 & 2.81 & & & & $\begin{array}{l}600 \\
-\end{array}$ & $\begin{array}{c}700 \\
-\end{array}$ & 2.71 \\
\hline
\end{tabular}

Table 3

Design capacities of the BRBs and the braced RC beams

\begin{tabular}{|c|c|c|c|c|c|c|}
\hline \multirow[b]{2}{*}{ Story } & \multicolumn{4}{|c|}{$\overline{B R B}$} & \multicolumn{2}{|c|}{ Braced RC beam } \\
\hline & $\begin{array}{c}A_{c} \\
\left(\mathrm{~mm}^{2}\right)\end{array}$ & $P_{y}(\mathrm{kN})$ & $\begin{array}{c}P_{T, \text { max }} \\
(\mathrm{kN})\end{array}$ & $\begin{array}{c}P_{C, \max } \\
(\mathrm{kN})\end{array}$ & $\begin{array}{c}0.7 T_{\max } \\
(\mathrm{kN})\end{array}$ & $0.7 T_{\max } / A_{s} F_{y n}$ \\
\hline $12 \mathrm{~F}$ & \multirow{2}{*}{900} & \multirow{2}{*}{293} & \multirow{2}{*}{456} & 525 & - & - \\
\hline $11 \mathrm{~F}$ & & & & & \multirow[t]{2}{*}{1176} & \multirow[t]{2}{*}{0.47} \\
\hline $\begin{array}{l}10 \mathrm{~F} \\
9 \mathrm{~F}\end{array}$ & 3600 & 1170 & 1825 & 2099 & & \\
\hline $8 \mathrm{~F}$ & \multirow{2}{*}{4000} & \multirow{2}{*}{1300} & \multirow{2}{*}{2028} & \multirow{2}{*}{2332} & 1986 & 0.49 \\
\hline $\begin{array}{l}7 F \\
6 F\end{array}$ & & & & & 2718 & 0.68 \\
\hline $5 \mathrm{~F}$ & 6400 & 2080 & 3245 & 3732 & \multirow{2}{*}{4286} & \multirow{2}{*}{0.91} \\
\hline $4 \mathrm{~F}$ & \multirow[t]{2}{*}{10000} & \multirow[t]{2}{*}{3250} & \multirow[t]{2}{*}{5070} & \multirow[t]{2}{*}{5831} & & \\
\hline $2 \mathrm{~F}$ & & & & & 4286 & 0.91 \\
\hline $1 \mathrm{~F}$ & 6400 & 2080 & 3245 & 3732 & - & - \\
\hline
\end{tabular}

Note: $A_{s}$ and $F_{y n}$ are the total cross-sectional area and nominal yield strength of the reinforcement, respectively.

\section{Test program}

\subsection{Subassembly Specimen}

The sub-assemblage specimen included a pair of RC corbels and a BRB gusset bracket. It had a 2470-mm-span beam and a column extending 1800$\mathrm{mm}$ high and 2010-mm high, respectively, above and below the joint. The reinforcement layout and detailed dimensions of the specimen are illustrated in Fig. 4. The beam cross section was $500 \times 600 \mathrm{~mm}$ and reinforced with 8 D25 longitudinal bars, while the column cross section was $600 \times 600 \mathrm{~mm}$ and reinforced with 16-D25 longitudinal bars. The column hoops and beam stirrups were D13 and D10 bars, respectively, spaced at $100 \mathrm{~mm}$ on centers in the plastic hinge zones, which increased to $150 \mathrm{~mm}$ outside the plastic hinge zones. Table 4 summarizes the averaged material strengths from the material tests.

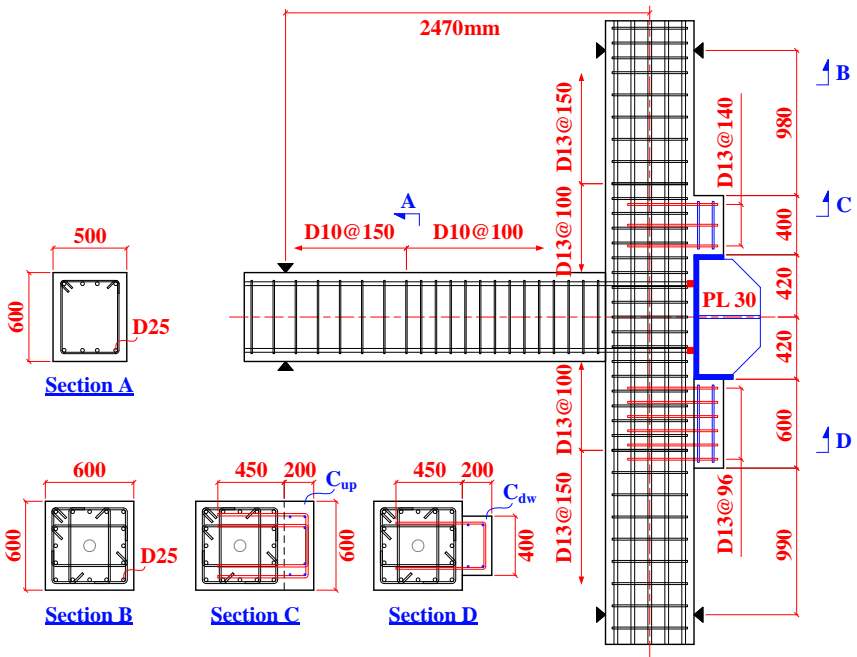

Fig. 4 Dimensions and reinforcement layout of the specimen

Table 4

Material test results

\begin{tabular}{ccccc}
\hline Material & $F_{y n}(\mathrm{MPa})$ & $\begin{array}{c}F_{y} \\
(\mathrm{MPa})\end{array}$ & $\begin{array}{c}F_{u} \\
(\mathrm{MPa})\end{array}$ & $\begin{array}{c}f_{c} \\
(\mathrm{MPa})\end{array}$ \\
\hline Longitudinal rebar, D25 (SD420) & & 454 & 669 & - \\
Column and corbel stirrup, D13 (SD420) & 420 & 451 & 686 & - \\
Beam stirrup, D10 (SD420) & & 437 & 663 & - \\
Gusset and bracket plate (A572 GR50) & 350 & 370 & 498 & - \\
Concrete & - & - & - & 47 \\
\hline
\end{tabular}

Note: $F_{y}$ and $F_{u}$ are the steel yield strength and tensile strength, respectively; $f_{c}$ is the concrete compressive strength on the day of testing.

\subsubsection{Design of gusset bracket}

In a traditional buckling-restrained braced frame, the BRB corner gusset is subjected to not only brace forces but also frame actions, which may lead to the premature failure of gusset connections and the impairment of the seismic performance of the system. In the proposed bracing system, there is no beam in the braced span. The gusset bracket connected with the two adjacent BRBs is attached to the side surface of the beam-to-column joint, thus preventing the frame action on the gusset. The gusset bracket is composed of a gusset plate joined to the BRBs and a U-shaped steel connected to the RC frame. It is designed as a force-controlled element to remain essentially elastic when the BRBs reach their expected maximum capacities. ASTM A572 GR50 steel (350 MPa as the nominal yield strength) was adopted for the gusset bracket of the specimen. The gusset plate was detailed on the basis of the BRB ends with the welded end-slot connection [2]. The design limit states, including tensile yielding, compressive buckling, and block shear failure [16], were considered to resist the design force demands. Welding between the gusset plate and the $\mathrm{U}$-shaped steel was designed to transfer the vertical resultant $V_{\max }$ from the two adjacent $\mathrm{BRBs}$ to the RC corbels and transfer the horizontal resultant of $0.7 T_{\max }$ to the longitudinal reinforcements of the braced RC beam. Dimensions of the gusset bracket specimen are shown in Fig. 4. Instead of applying two physical BRB members, four electro-servo hydraulic actuators were used to simulate the horizontal and vertical resultants developed from the BRBs. Thus, to transfer the gusset normal forces from a pair of actuators, a transfer plate was welded onto the gusset free edge of the gusset and Ushaped steel bracket assembly. The U-shaped steel end plate was also extended outward and properly stiffened, as shown in Fig. 5, to attach another pair of actuators for applying the corbel shear.

\subsubsection{Design of corbel}


The RC corbels in the structural system are also considered as the forcecontrolled element, which are expected to resist the vertical shear demand of $V_{\max }$ coming from the gusset bracket. When the two adjacent BRBs reached their maximum capacities $P_{T, \max }$ and $P_{C, \max }$ (Table 3 ), the calculated shear demands of the corbels above and below the specimen gusset bracket were 1729 and $1590 \mathrm{kN}$, respectively. In the proposed connection, however, the gusset bracket is connected to the beam longitudinal reinforcements via the couplers. The beam longitudinal reinforcements can resist the horizontal tension from the BRBs directly and provide vertical shear resistance indirectly. Thus, the shear demands on the pair of corbels are reduced. To prevent an excessively conservative design result, the target shear capacities of the upper $\left(C_{\text {up }}\right)$ and lower $\left(C_{\mathrm{dw}}\right)$ corbels were designed as $60 \%$ and $70 \%$ of the abovementioned shear demands, respectively. As shown in Table 5 and Fig. 4, the depths $(H)$ of corbels $C_{\text {up }}$ and $C_{\mathrm{dw}}$ were 400 and $600 \mathrm{~mm}$, while their widths $(B)$ were 600 and $400 \mathrm{~mm}$, respectively. The lengths $(L)$ of both corbels were $200 \mathrm{~mm}$, and the length-to-depth ratios $L / H$ were 0.5 and 0.33 , respectively. Corbel $C_{\text {up }}$ was reinforced by $140 \mathrm{~mm}$ spaced D13 U-shaped double stirrups, while Corbel $C_{\mathrm{dw}}$ was reinforced by $96 \mathrm{~mm}$ spaced D13 U-shaped single stirrups. The corbel stirrups were $450 \mathrm{~mm}$ embedded into the column surface and were secured by framing bars.

The shear resisting capacity $V_{u}$ of the corbels was assessed considering the modified strut-and-tie model [17]:

$V_{u}=\sigma_{d} B l \cos \theta$

where $\sigma_{d}, \theta$, and $l$ are the softened compressive strength, inclination, and depth of the concrete strut, respectively.

$\sigma_{d}=\left\{\begin{array}{l}\frac{0.9 f_{c}}{\sqrt{1+400 f_{c t} / E_{c}}} \text { for } f_{c}<42 \mathrm{MPa} \\ \frac{5.8 \sqrt{f_{c}}}{\sqrt{1+400 f_{c t} / E_{c}}} \text { for } f_{c} \geq 42 \mathrm{MPa}\end{array}\right.$

$l=k d=\left(\sqrt{\left(n \rho_{s}\right)^{2}+2 n \rho_{s}}-n \rho_{s}\right) d$

$\theta=2 \tan ^{-1}\left(\frac{-1+\sqrt{(a / d)^{2}+\left(1+k^{2} / 4\right)}}{a / d-k / 2}\right)$

where $f_{c t}$ is the concrete tensile strength; $n=E_{s} / E_{c}$ is the ratio of steel to concrete elastic moduli; $d$ and $\rho_{s}$ are the corbel effective depth and primary stirrups ratio, respectively; and $a$ is the applied force center-to-column surface distance. According to the assumption of the stirrup stress distribution along the corbel depth in this approach, the effective depth of the tie and the effective stirrup ratio can be calculated as follows:

$d=\frac{2}{3} H$

$\rho_{s}=0.5 \frac{n_{l e g} A_{s 1}}{B d}$

where $n_{\text {leg }}$ and $A_{s 1}$ are the number of stirrup legs and the cross-sectional area of a single stirrup leg, respectively. The concrete tensile strength $f_{c t}$ was specified as $0.1 f_{c}$, while the steel and concrete moduli were assumed to be $E_{s}=200 \mathrm{GPa}$ and $E_{c}=4.7 \sqrt{f_{c}(\mathrm{MPa})} \mathrm{GPa}$. As a result, the shear resisting capacities of corbels $C_{\mathrm{up}}$ and $C_{\mathrm{dw}}$ were determined to be 1079 and $1097 \mathrm{kN}$ (Table 5). On the other hand, simple design provisions based on shear friction theory are provided in ACI 318-11 to evaluate the corbel shear resistance $V_{n}$ [15]:

$$
V_{n}=A_{v f} F_{y} \mu \leq\left(0.2 f_{c} A_{c o n}, 5.5 A_{c o n}\right)
$$

where $A_{\text {con }}$ is the area of concrete section resisting shear transfer; $\mu$ and $A_{v f}$ are the friction coefficient and the area of shear-friction reinforcement. All the U-shaped stirrups in the corbel were accounted for the area of the shearfriction reinforcement, while the friction coefficient of 1.4 was adopted for monolithically cast concrete. Consequently, the shear resistance of corbels $C_{\text {up }}$ and $C_{\mathrm{dw}}$ was $877 \mathrm{kN}$, which is more conservative than the resistances evaluated using the former method.
Table 5

Corbel design results

\begin{tabular}{cccccccccc}
\hline Corbel & $L(\mathrm{~mm})$ & $H(\mathrm{~mm})$ & $B(\mathrm{~mm})$ & $a(\mathrm{~mm})$ & $\begin{array}{c}n_{\text {leg }} \\
(\mathrm{mm})\end{array}$ & $k$ & $\begin{array}{c}\rho_{s} \\
(\%)\end{array}$ & $\theta$ & $\begin{array}{c}V_{u} \\
(\mathrm{kN})\end{array}$ \\
\hline $\mathrm{C}_{\mathrm{up}}$ & 200 & 400 & 600 & 50 & 12 & 0.23 & 0.48 & $17^{\circ}$ & 1079 \\
$\mathrm{C}_{\mathrm{dw}}$ & 200 & 600 & 400 & 50 & 12 & 0.23 & 0.48 & $14^{\circ}$ & 1097 \\
\hline
\end{tabular}

\subsection{Test Setup and Loading Procedure}

As shown in Figs. 4 and 5, the sub-assemblage specimen was rotated $90^{\circ}$ to have corbels $C_{\mathrm{up}}$ and $C_{\mathrm{dw}}$ located at the north and south sides, respectively. Two assumed inflection points of the column were constrained using steel fixtures to simulate the north and south ends as a pin and a roller supports, respectively. The column was compressed to $700 \mathrm{kN}$ using a post-tensioned rod through the column center to simulate the gravity load effect. The displacement-controlled horizontal actuator (BD) was connected to the beam end to simulate the equivalent inter-story drifts when the structural frame was subjected to lateral loads. The corbel shear resulting from the vertical resultant of the two BRBs was imposed to the specimen using two horizontal force-controlled actuators connected to the east and west sides of the gusset bracket (V1 and V2). A stiffened steel transfer beam, attached to the transfer plate on the gusset free edge, was connected with two vertical actuators installed on the strong floor $(\mathrm{H} 1$ and $\mathrm{H} 2)$ to impose the horizontal resultant of the BRBs. Another steel transfer beam, attached to the cantilever beam end, was connected with two other vertical actuators (BA1 and BA2) to allow the imposition of axial force variations to the RC beam through the abovementioned transfer beam attached to the gusset. The applied horizontal resultants of the BRBs were the sum of the forces from the four actuators, $\mathrm{H} 1$, $\mathrm{BA} 1, \mathrm{BA} 2$, and $\mathrm{H} 2$, while the beam axial loads were only from actuators BA1 and BA2. All actuators have a push or pull force capacity of $980 \mathrm{kN}$. The test setup adopted by Qu et al. [11] included the BRB members, which is trusted to be the state-of-the-art approach for evaluation of BRB connections. Test results confirmed that the gusset connection in the novel bracing system performed well despite the BRB end rotational demands induced by the beam-to-column joint translation and rotation. It is judged that the rotational demands imposed from the BRB end gussets on the proposed connection are less critical in the current study as the gusset bracket is fully anchored into the RC beam-to-column joint using beam longitudinal reinforcements. The flexural capacity of the BRB core can be conveniently computed and incorporated into the beam reinforcement design to resist the additional force from such rotational demand. Thus, in order to simplify the test setup, only shear and tension are imposed on the proposed connection without rotations.

The 12-story prototype building was analyzed using a detailed PISA3D model with the specified elements and material properties described in the next section. A cyclic loading analysis was conducted on the PISA3D building model by applying three cycles to each with roof or story drift ratios of $0.2 \%, 0.25 \%, 0.35 \%, 0.5 \%, 0.75 \%, 1.0 \%, 1.4 \%, 1.75 \%, 2.2 \%, 2.75 \%$, and $3.5 \%$ in sequence, as prescribed in ACI 374.1-05 [18]. Using the aforementioned seven actuators, the sequence of the loading amplitudes for the sub-assemblage specimen was based on the PISA3D analytical results to impose cyclic drifts to the cantilever beam end, the corresponding BRB force resultants, and the beam axial forces on the beam-to-column joint. As shown in Figs. 1(c) and 5, loadings toward the X-direction of the structural frame, the north, and the upward directions of the specimen were taken to be positive.

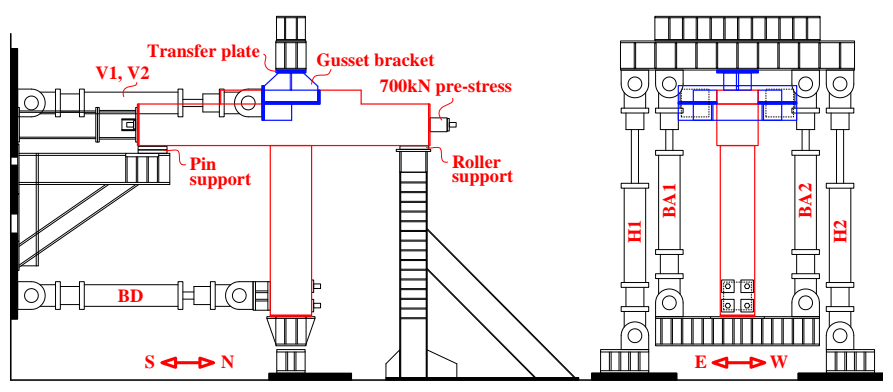

Fig. 5 Test setup

\section{Experimental results and discussion}

\subsection{RC Member Response}

During the loadings with $0.5 \%$ drift ratio, the beam and column elements remained essentially elastic as expected and no evident crack was observed on the sub-assemblage. The free body diagram of the specimen is depicted in Fig. 
6. The work point of the two BRBs was set at the column surface rather than the column centerline. Therefore, the vertical resultant $V_{B R B}$ from the gusset bracket provided a moment demand of $V_{B R B} \times h / 2$ on the column. Although the arm was short, significant forces in the BRBs were able to make the resultant moment contribution comparable to that of the eliminated beam. This moment demand on the column must be considered. The total column moment resistance $V_{c 1} \times H_{1}+V_{c 2} \times H_{2}$ in the sub-assemblage was obtained by combining the contribution of the beam moment $V_{b} \times L_{b}$ ( $L_{b}$ is measured from the cantilever load to the column centerline) and that of the BRBs $V_{B R B} \times h / 2$. As shown in Fig. 7(a), the maximum moment contribution of the BRBs was about half that of the beam and about one-third of the total moment resistance of the specimen. Fig. 7(b) compares the test results with the P-M curves computed from the beam section analysis; the beam moment responses agreed with the predicted yielding surface. When the frame roof drift was positive, the corresponding beam end deformation of the specimen was negative, and the beam was compressed by the BRB horizontal resultant. Both analytical and experimental results indicated that the beam moment resistance in compression was larger than that in tension. Specimen damage conditions (Fig. 8) at the end of the test revealed that concrete spalling occurred at the beam fixed end, which is in compliance with the strong column-weak beam design principle. The flexural-shear cracks of the column appeared only within the range between the two corbels. Thus, it appears from the beam P$\mathrm{M}$ responses that the flexural behavior of the beam was not evidently influenced despite its longitudinal reinforcements are connected to the gusset bracket.

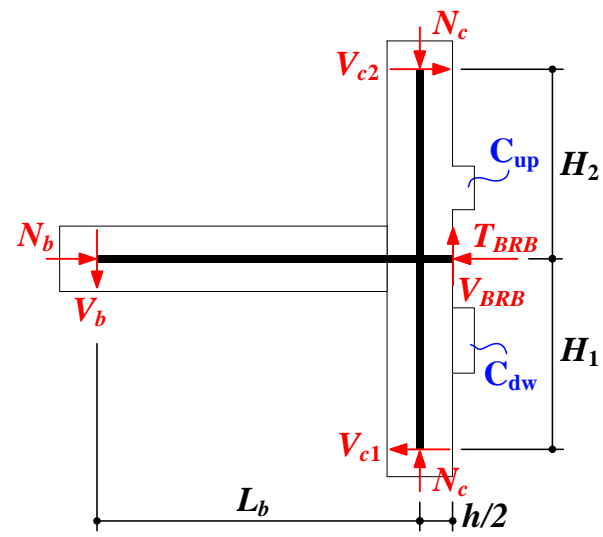

Fig. 6 Free body diagram of the sub-assemblage specimen

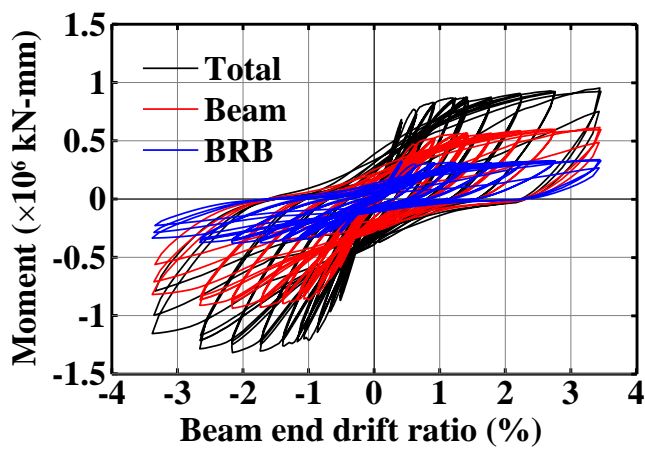

(a)

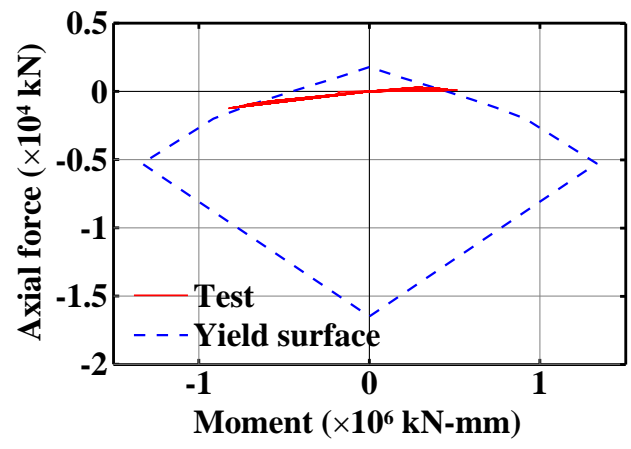

(b)

Fig. 7 (a) Bending moment components in the sub-assemblage specimen and (b) comparison of the experimental beam axial force versus moment relationships with the P-M yield surface
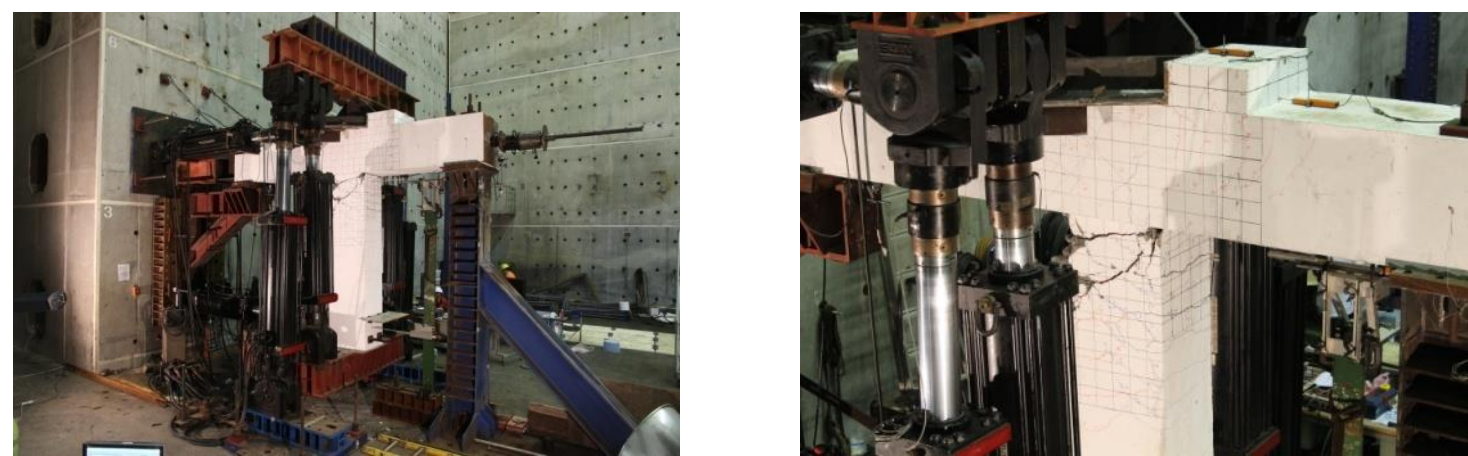

Fig. 8 Damage condition of specimen at the end of testing

\subsection{Gusset Bracket and Corbel Response}

The gusset bracket remained elastic and worked rather well throughout the entire test. The gusset bracket force versus displacement relationships in the direction normal to the column surface are shown in Fig. 9(a). The maximum displacement measured was less than $0.5 \mathrm{~mm}$, which was small enough to be ignored. When the gusset bracket was compressed, the measured small positive normal displacements, shown in Fig. 9(a), were most likely caused by the slip of the measurement gauges or the local elastic deformation of the gusset bracket. Cyclic upward pull tests on the gusset bracket were continued after the prescribed cyclic loading test on the sub-assemblage. At the end of test, the maximum tensile force sustained by the gusset bracket was about $1800 \mathrm{kN}$ without nonlinear behavior observed. Corbel shear versus deformation relationships for $C_{\mathrm{up}}$ and $C_{\mathrm{dw}}$ are shown in Fig. 9(b). During the entire tests, there was almost no crack found on the two corbels and only slight crush of the concrete was observed at the corbel edges due to bearing pressure from the gusset bracket. After the cyclic loading test, both corbels were monotonically pushed until the actuators reached their maximum capacities. No evident damage to the two corbels was observed before the end of testing. This could be attributed to the fact that the gusset bracket was cast with the column and corbels at the same time, there is no gap or non-shrike grout between the steel bracket and concrete surface. The behavior of the corbels was not affected by the deformation and flexural-shear cracks in the column adjacent to the corbels and in the panel zone. Test results confirm that the two corbels can carry much more shear resistance than the expected design capacity. It appears that the beam longitudinal reinforcements anchored on the back of the gusset bracket had provided a significant additional shear friction resistance. 


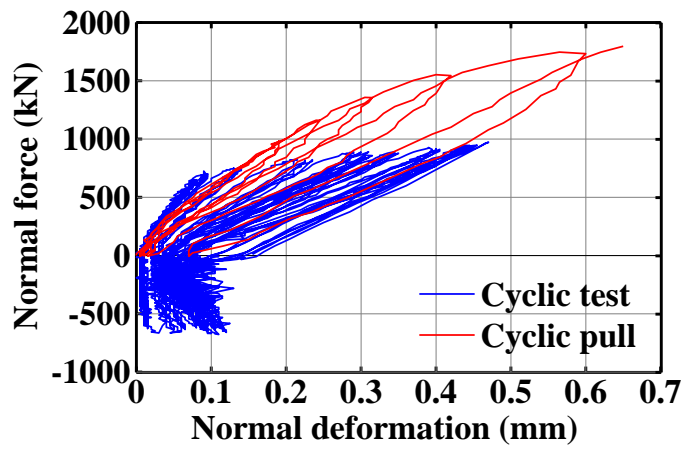

(a)

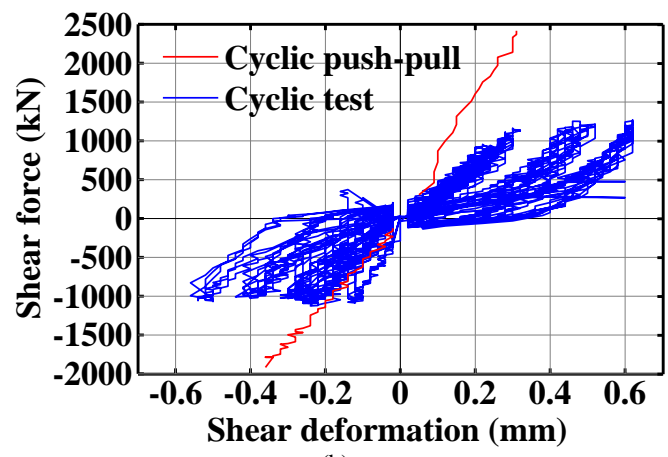

(b)

Fig. 9 (a) Gusset bracket normal force versus displacement relationships and (b) corbel shear versus deformation relationships

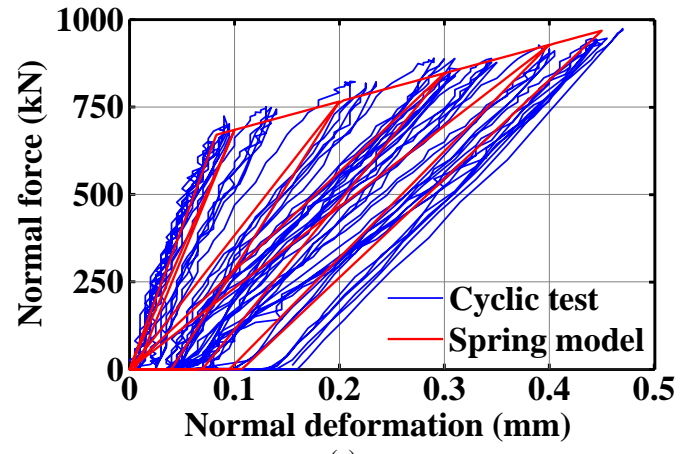

(a)

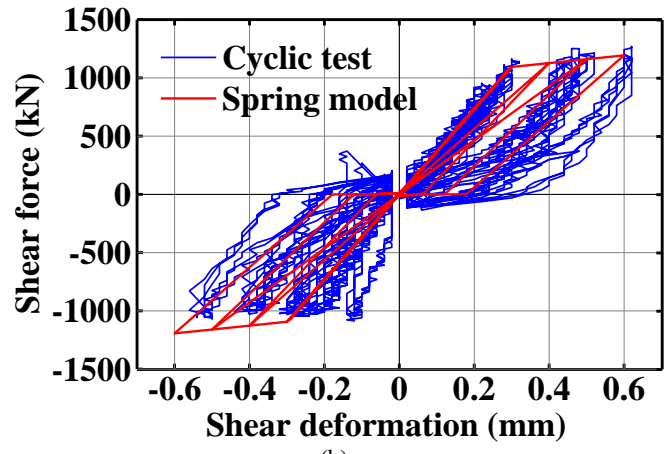

(b)

Fig. 10 Spring models for (a) the gusset bracket and (b) the corbels
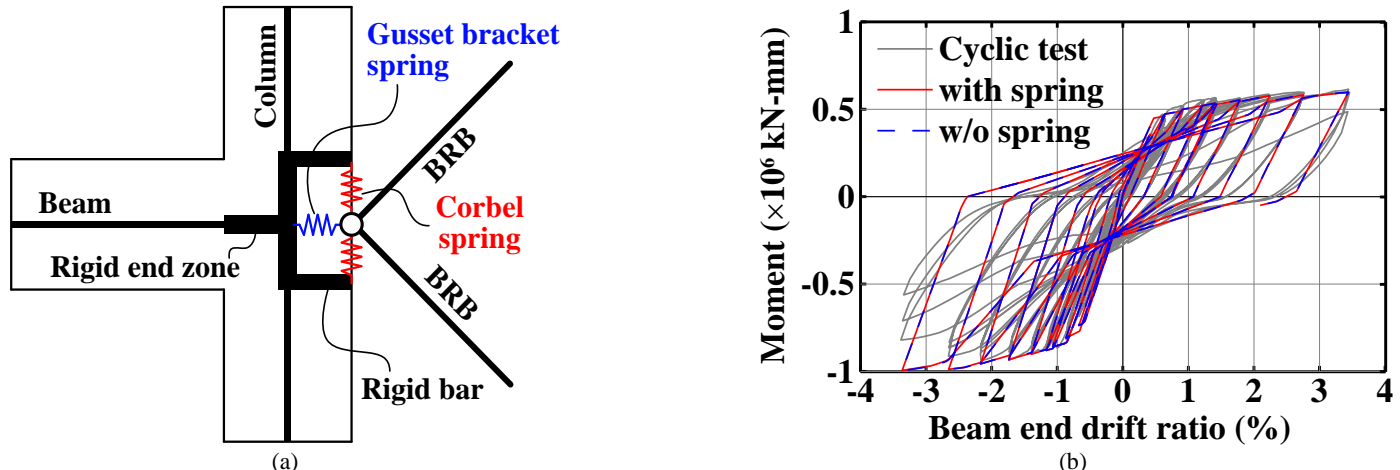

(b)

Fig. 11 (a) Equivalent springs for the proposed BRB connection and (b) experimental and analytical results of the specimen

\subsection{Numerical Modeling of the Connection between the BRB and RC Frame}

The effectiveness of BRB-to-RC frame connections is critical to the seismic performance developed from the BRBs during earthquakes. In this section, the force-deformation behavior of the gusset bracket and corbels is simulated using equivalent spring models to investigate the effects of connection flexibility on seismic responses of the entire system. The built-in degrading material in PISA3D was adopted for the equivalent spring to simulate the stiffness degradation and residual deformation of the gusset bracket tension behavior (Fig. 10(a)). This degrading material was also adopted to model the shear responses of corbels (Fig. 10(b)). A detailed PISA3D analytical model of the sub-assemblage specimen, as shown in Fig. 11(a), was then constructed with and without the above-mentioned equivalent springs placed at the BRB work point. The adopted elements and material properties will be described in the next section. The boundary conditions and loading procedures in the analytical model were arranged in accordance with the test setup. Analytical results shown in Fig. 11(b) indicate that both PISA3D models with and without the equivalent springs capture the specimen behavior satisfactorily. The minor differences between the responses of the two models confirm that the proposed connection effectively suppress the unfavorable influence of the connection flexibility on the system behavior.

\section{Analytical investigation of the prototype}

The composite sections of RC members were simulated using fiber beamcolumn elements. Reinforcing bars were modelled using the three-parameter degrading material to simulate the concrete bond slip and pinching behavior of the hysteresis loop, as shown in Fig. 12. The Popovics [19] and KarsanJirsa [20] models were adopted to define the concrete compressive stressstrain response envelope and the degrading linear unloading/reloading stiffness, respectively. BRBs were represented by truss elements and defined as a hardening material, which takes the combined effects of the isotropic and kinematic hardening into account [2]. The BRB work points, the arrangements for the rigid ends at the beam-to-column joints, the concrete floor slab elements, and the constraint conditions in the PISA3D model were the same as those in the above-mentioned SAP2000 model. As illustrated previously, it is verified that the proposed connection deformation responses due to the gusset bracket normal force and corbel shear are small enough to be neglected. Thus, the equivalent springs representing the connection behavior were excluded in the analytical model to improve the computational efficiency. The dynamic analyses were conducted using a total of 240 earthquake records [21] with 80 for each of the service-level earthquake (SLE), design-basis earthquake (DBE), and maximum-considered earthquake (MCE) levels. These ground motions, including near-fault events, were normalized according to the estimated fundamental period of the building and the design response spectrum for Chiayi City (Fig. 13) 


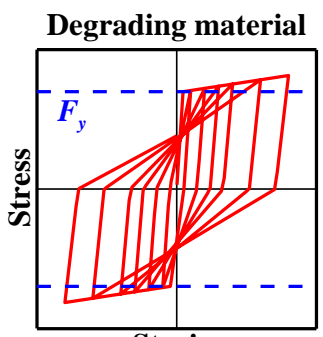

Strain
Concrete material

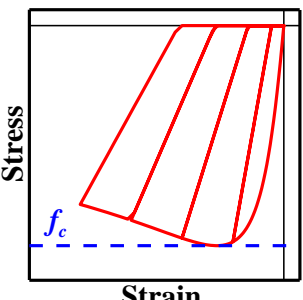

Strain
Hardening material

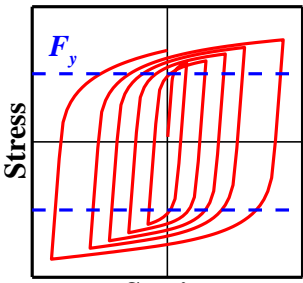

Strain

Fig. 12 Material properties for the PISA3D model
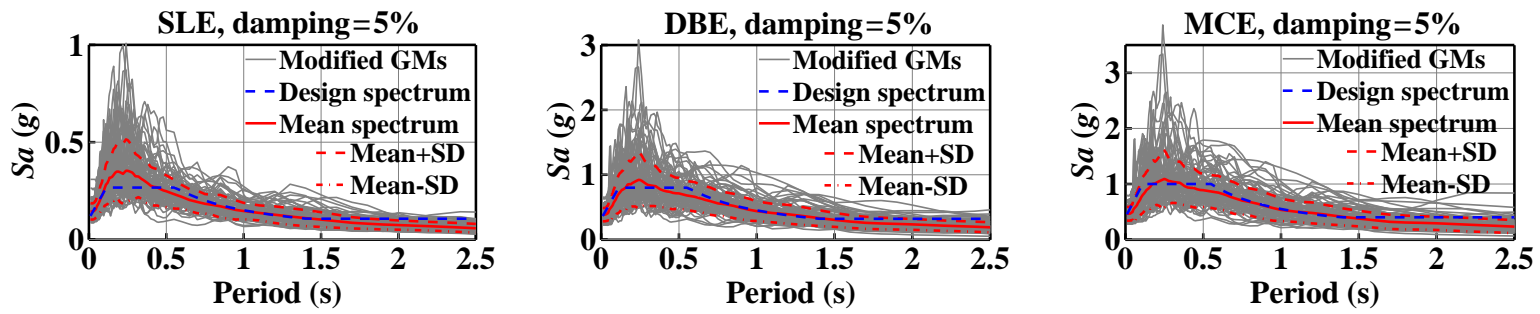

Fig. 13 Modified ground motions for the three hazard levels

\subsection{Overall Structural Response}

Fig. 14(a) shows that the maximum inter-story drift responses under SLE, DBE, and MCE events were $0.55 \%, 1.82 \%$, and $2.32 \%$, while the averaged ratios were $0.33 \%, 0.9 \%$, and $1.11 \%$, respectively. It appears that lateral deformations of this prototype building were effectively controlled because of the BRB stiffness contribution and the design safety requirements for hospitals. The mean values of the maximum base shears (Fig. 14(b)) were 8404, 18220, and $20630 \mathrm{kN}$ under SLEs, DBEs, and MCEs, respectively. In comparison with the design base shear of $7517 \mathrm{kN}$, the system overstrengths were 1.1, 2.4, and 2.7 for the three hazard levels, respectively. Fig. 15(a) shows the maximum horizontal shears provided by the pair of bottom BRBs, which indicate that the BRBs exceeded their yield strengths under DBEs and MCEs. The maximum ratios of the total BRB shears (horizontal resultants) to their corresponding base shears, shown in Fig. 15(b), had mean values of around 19\% (MCE), 21\% (DBE), and 23\% (SLE). Analytical results reveal that the BRBs remained elastic and the BRB shear contribution to the base shear was close to the design value of $28 \%$ during small earthquake events. During moderate and strong earthquakes, the BRBs absorbed seismic energy by yielding and the BRB shear contribution was then reduced with a rising shear contribution from the RC moment frame.

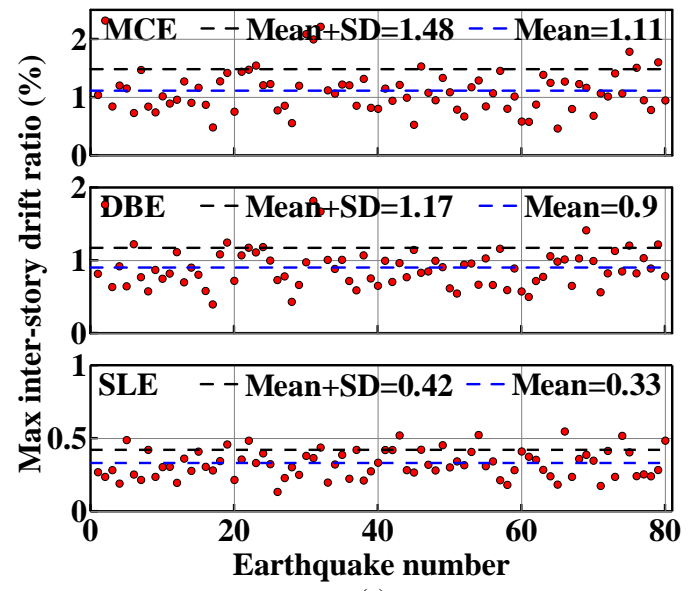

(a)

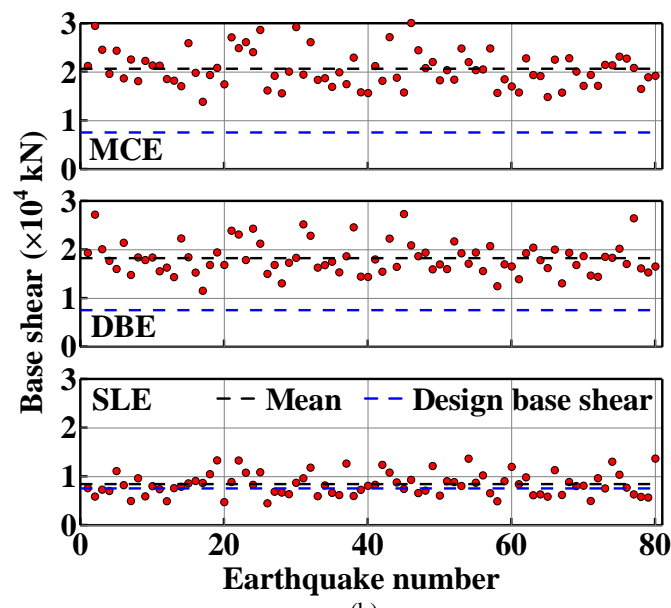

(b)

Fig. 14 Maximum (a) inter-story drift ratios and (b) base shear responses

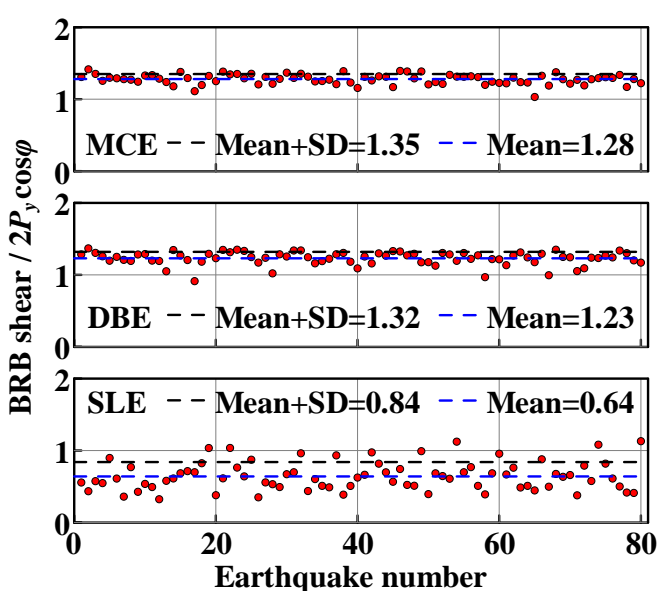

(a)

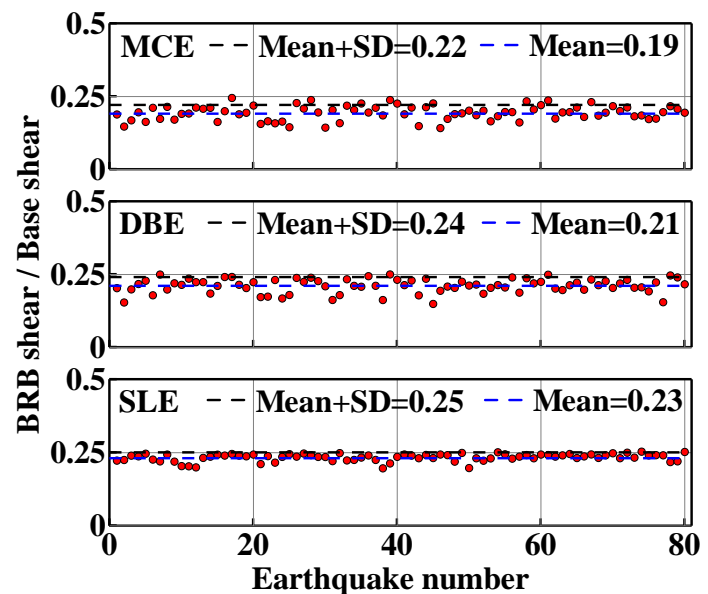

(b)

Fig. 15 Maximum BRB (a) shear responses and (b) shear contributions 


\subsection{BRB to RC Frame Nodal Force Response}

When the structural system is subjected to the first-mode vibration, the two adjacent BRBs are subjected to tension and compression. The shear demand $V_{\max }$ of corbels is considered as the vertical resultant induced from the BRB maximum strengths $P_{T, \max }$ and $P_{C \text {, max }}$. The dynamic analyses shown in Fig. 16(a) indicate that the maximum vertical resultant $V_{B R B}$ reached $0.96 V_{\max }$ during MCEs as expected. Without considering the higher modes of
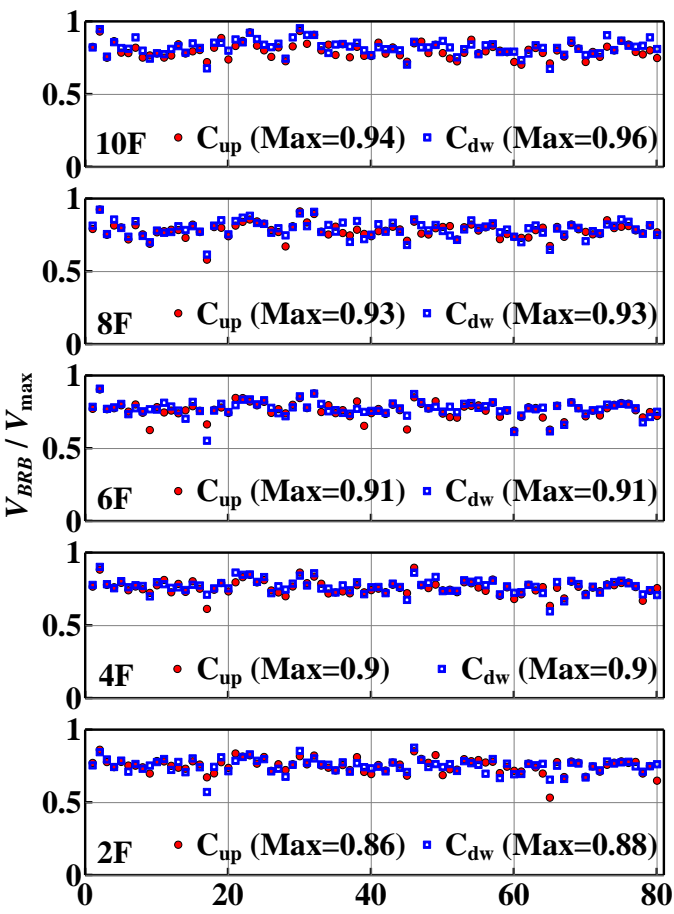

Earthquake number (MCE)

(a) the system, the horizontal components of the two adjacent BRBs counteract each other and thus impose very small demands on the braced beam. However, significant horizontal resultants caused by the BRBs may arise due to the system higher mode vibrations, especially after the BRBs yield and the first mode vibration is greatly suppressed. As shown in Fig. 16(b), the maximum horizontal tension $\left(T_{B R B}\right)$ and compression $\left(C_{B R B}\right)$ reached $0.7 T_{\max }$ and $0.68 C_{\max }$ during MCE events, respectively.

Fig. 16 Maximum BRB (a) vertical and (b) horizontal resultants

\subsection{Braced Beam Response}

In this section, the analytical results of the ground acceleration MCE No. 2 with the maximum inter-story drift response among the 80 sets of analyses (Fig. 14(a)) are selected to illustrate the braced beam's seismic response. The beam axial force versus moment response for the tenth floor braced beam (Fig. 17) was satisfactorily bounded by the calculated yield surface, showing the accuracy of the PISA3D fiber beam-column elements in the simulation of the RC member's P-M interactions. The time histories of the BRB horizontal resultant and the braced beam axial force at the tenth floor joint are compared in Fig. 18(a). When the BRB horizontal resultants were toward the braced beam as negative values in the plot, the BRB nodal forces could be transferred into the braced beam directly. However, when the BRB horizontal resultants were outward, the nodal forces could not be balanced by the braced beam tensile forces and the margins must be transmitted into the column shears. The analytical results, using the same ground motion of MCE No. 2 but applied in the reversed direction, are shown in Fig. 18(b). The seismic peak response of the BRB horizontal resultant and the braced beam axial force were somewhat different than those computed from the same ground motion imposed in the opposite direction. This is because the RC beam axial stiffness under tension is smaller than that under compression.

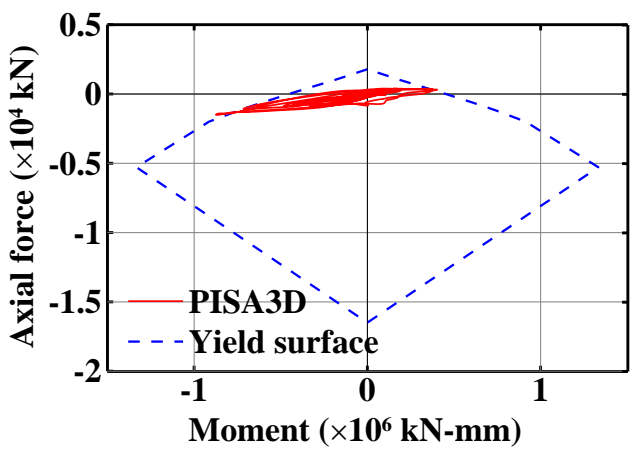

Fig. 17 Beam moment responses at the tenth floor beam-to-column joint

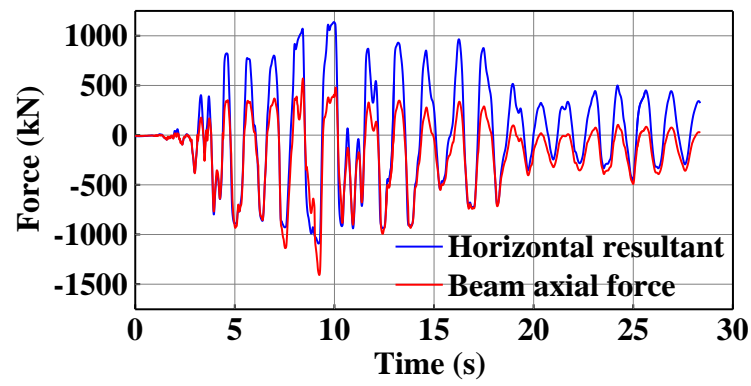

(b)

Fig. 18 Time histories of BRB horizontal resultants and braced beam axial forces under (a) MCE No. 2 and (b) reversed MCE No. 2 ground motions 


\section{Conclusions}

1. This proof-of-concept test confirms the feasibility of the proposed system for practical applications. Test results indicate that the beam moment resistances were in compliance with the predicted yield surface. No eviden damage to the two corbels was observed before the end of testing. This could be attributed to the fact that the gusset bracket was cast with the column and corbels at the same time, there is no gap or non-shrike grout between the steel bracket and concrete surface.

2. The design shear capacity computed using ACI specifications for the proposed connection corbels is very conservative. It is confirmed that the beam longitudinal reinforcements anchored on the gusset bracket can provide a significant additional shear friction resistance. Test results indicate that the proposed gusset anchor details can lead to a much stronger connection than that tested by others. However, RC corbels may fail in a very brittle manner under shear. It is recommended that the corbel shear resistance be at least computed from the modified strut-and-tie model to ensure an effective connection between the $\mathrm{BRB}$ and $\mathrm{RC}$ frame.

3. NLRHA results of the prototype building show that the maximum ratios of the total BRB shear to base shear are $23 \%, 21 \%$, and $19 \%$ in the SLE,

\section{References}

[1] Wada A. and Nakashima M., "From infancy to maturity of buckling restrained braces research", Proceedings of the 13th World Conference on Earthquake Engineering, Vancouver, B.C., Canada, 2004

[2] Tsai K.C., Wu A.C. Wei, C.Y., Lin P.C., Chuang M.C. and Yu Y.J., "Welded end-slot connection and debonding layers for buckling-restrained braces", Earthquake Engineering \& Structural Dynamics, 43(12), 1785-807, 2014.

[3] Takeuchi T. and Wada A., "Buckling-Restrained Braces and Applications", The Japan Society of Seismic Isolation, 2017.

[4] Mahrenholtz C., Lin P.C., Wu A.C., Tsai K.C., Hwang S.J., Lin R.Y. and Bhayusukma M.Y., "Retrofit of reinforced concrete frames with buckling-restrained braces", Earthquake Engineering \& Structural Dynamics, 44(1), 59-78, 2015.

[5] Pan K.Y., Wu A.C., Tsai K.C., Li C.H. and Khoo H.H., "Seismic retrofit of reinforced concrete frames using buckling-restrained braces with bearing block load transfer mechanism", Earthquake Engineering \& Structural Dynamics, 45(14), 2303-2326, 2016.

[6] Takeuchi T., Yasuda K. and Iwata M., "Studies on Integrated building facade engineering with high-performance structural elements", Proceedings of International Association for Bridge and Structural Engineering Symposium, Budapest, Hungary, 2006.

[7] Robinson K., "Novel uses for the buckling restrained brace", Structure Magazine, August, 2012

[8] Richards J., " $\$ 48.5$ million parking structure at John Wayne Airport is braced for the future", Airport Improvement Magazine, March-April, 2011.

[9] Viano J.D. and Schaeffer T.C., "Novel use of buckling-restrained braces in precast concrete frames", PCI Journal, 62(5), 28-34, 2017

[10] Wu A.C., Tsai K.C., Yang H.H., Huang J.L., Li C.H., Wang K.J. and Khoo H.H., "Hybrid experimental performance of a full-scale two-story buckling-restrained braced RC frame", Earthquake Engineering \& Structural Dynamics, 46(8), 1223-1244, 2017.
DBE, and MCE events, respectively. BRBs remain elastic during the SLEs and go into the inelastic range to dissipate seismic energy under the DBEs and MCEs as expected.

4. NLRHA results suggest that the horizontal tension demand of the proposed gusset connection due to the system higher mode vibrations can be taken as $70 \%$ of the maximum tensile strengths $\left(0.7 T_{\max }\right)$ of the two adjacent BRBs. However, for the design of higher or more irregular buildings than the proposed prototype, it is recommended that the effects of the system dynamic responses on the BRB connections be evaluated specifically.

5. Significant horizontal force demands could occur on the BRB connection at the top and bottom stories, or when the two adjacent BRBs have notably different strengths. In addition, for BRBs connected to the top and bottom beams or columns without using corbels, the shear failure of the RC discontinuity regions due to the concentrated loads from the BRB must be prevented.

6. Imposing the same ground motions in two opposite directions, the magnitudes of the peak BRB horizontal resultant and the braced beam axial force responses were different. This is because the RC beam axial stiffness under tension is smaller than that under compression.

[11] Qu Z., Kishiki S., Sakata H., Wada A. and Maida Y., "Subassemblage cyclic loading test of RC frame with buckling restrained braces in zigzag configuration", Earthquake Engineering \& Structural Dynamics, 42(7), 1087-102, 2013

[12] Qu Z., Kishiki S., Maida Y., Sakata H. and Wada A., "Seismic responses of reinforced concrete frames with buckling restrained braces in zigzag configuration", Engineering Structures, 105, 12-21, 2015

[13] Lin B.Z., Chuang M.C. and Tsai K.C., "Object-oriented development and application of a nonlinear structural analysis framework", Advances in Engineering Software, 40(1), 66-82, 2009 .

[14] Computers and Structures, Inc. https://www.csiamerica.com/products/sap2000.

[15] ACI, Building code requirements for structural concrete and commentary (ACI 318-11), American Concrete Institute, Farmington Hills, Michigan, 2011

[16] Chuang M.C., Tsai K.C., Lin P.C. and Wu A.C., "Critical limit states in seismic buckling-restrained brace and connection designs", Earthquake Engineering \& Structural Dynamics, 44(10), 1559-1579, 2015.

[17] Qu Z., Maida Y., Kishiki S. and Sakata H., "Shear resistance of reinforced concrete corbels for shear keys", Proceedings of the 9th International Conference on Urban Earthquake Engineering and 4th Asia Conference on Earthquake Engineering, Tokyo, Japan, 2012.

[18] ACI, Acceptance criteria for moment frames based on structural testing and commentary (ACI 374.1-05), American Concrete Institute, Farmington Hills, Michigan, 2005.

[19] Popovics S., "A numerical approach to the complete stress-strain curve of concrete", Cement and Concrete Research, 3(5), 583-599, 1973.

[20] Karsan I.D. and Jirsa J.O., "Behavior of concrete under compressive loadings", Journal of the Structural Division, 95, 2543-2563, 1969

[21] Baker J.W., Lin T., Shahi S.K. and Jayaram N., New ground motion selection procedures and selected motions for the PEER transportation research program, Pacific Earthquake Engineering Research Center, Berkeley, California, 2011. 